doi 10.7213/comunicao.35.014AO08 e-ISSN 1982-8675 Licenciado sob uma Licença Creative Commons

\section{Espaço urbano como comunicação: signos da paisagem}

\section{Urban space as communication: \\ signs of landscape}

\author{
Lucia Teresinha Peixe Maziero ${ }^{\text {[a] }}$,
} João Henrique Bonametti ${ }^{[b]}$

\section{Resumo}

Neste artigo são apresentados conceitos clássicos de semiótica aplicados às linguagens do espaço urbano, tendo como foco a compreensão da comunicação resultante da cognição humana na percepção da cidade. Construiu-se um roteiro conceitual, com base na semiótica e na psicologia cognitiva, para discutir a ação dos signos da paisagem, produzidos pelo homem e pela natureza. Propôs-se uma abordagem analítica, gerando uma rotina de pensamento a ser utilizada como meio de potencializar a condição comunicativa do espaço urbano na identificação e compreensão das linguagens que se manifestam. Como recorte da paisagem urbana, utilizou-se o exemplo de [a] Doutora em Cartografia e

Geoprocessamento pela Universidade Federal do Paraná (UFPR), professora de Projeto de Paisagismo e Semiótica da Escola de Arquitetura e Design da Pontifícia Universidade Católica do Paraná (PUCPR), Curitiba, PR- Brasil, e-mail: lucia.maziero@pucpr.br

[b] Arquiteto e urbanista, doutor em História Social pela Faculdade de Filosofia, Letras e Ciências Humanas da Universidade de São Paulo (USP), professor de Projeto de Paisagismo, História da Arquitetura, coordenador do curso de Especialização em Arquitetura da Paisagem da Pontifícia Universidade Católica do Paraná (PUCPR), Curitiba, PR- Brasil, e-mail: joão.bonametti@pucpr.br

Palavras-chave: Comunicação. Espaço urbano. Semiótica. 
análise sobre um parque contemporâneo. Relacionandose os significados corporificados no espaço com aqueles que existem apenas no imaginário das pessoas, observa-se a transformação do lugar, priorizando resultados à sociedade e à valorização individual e coletiva. A temática da comunicação do ambiente urbano pode trazer avanços nas abordagens conceituais e metodológicas, visando a um novo formato de produção de conteúdo sobre o modo de pensar as cidades.

\section{Abstract}

This article presents the classical concepts of semiotics applied in the languages of urban space, focusing on the Keywords: Communication. understanding of the communication resulting from the human cognition in the perception of the city. It builds a conceptual roadmap, based on semiotics and cognitive psychology, to discuss the action of signs of the landscape, produced by man and nature. It proposes an analytical approach, generating a thinking routine to be used as a means of enhancing the urban space communicative condition in the identification and understanding of languages that are manifested. As an urban landscape cut, it uses the example of analysis on a contemporary park. Relating the meanings embodied in space with those that exist only in the imagination of people, it observes the transformation of places, prioritizing results to society and the individual and collective appreciation. The issue of communication of the urban environment may bring advances in conceptual and methodological approaches, aiming at a new format to produce content about the way of thinking about cities.

\section{Introdução}

No que concerne à comunicação, o espaço urbano é um grande e variado ambiente de interação, no qual não se constroem imagens isoladas representando sua diversidade de informações. Pessoas estão na rua e produzem relações de vivência social em seu cotidiano. Nesse diálogo 
com o mundo, vivenciam um complexo sistema de informações, no qual o conhecimento é produzido a partir das suas relações com o meio. Há de se entender como esse conhecimento é representado. Constitui-se desafio identificar meios de potencializar a comunicação no modo de pensar as cidades. Devem ser buscadas formas de potencializar essa comunicação, por meio da inserção de novas tecnologias e novas rotinas de pensamento, especialmente voltadas à valorização do indivíduo e do coletivo.

Em um processo de comunicação, torna-se necessário caracterizar os interlocutores: de um lado, tem-se a cena do ambiente construído - realidade externa, como fonte de informações em uma imagem coletiva; de outro, tem-se indivíduos - interpretadores das informações, construindo suas representações internas e formando um modelo mental. Nesse sentido, este ensaio sobre linguagens do espaço urbano tem foco principal na comunicação resultante da cognição humana na percepção do lugar. Tem-se a intenção de discutir a ação das linguagens presentes, buscando-se, principalmente, compreender como ocorre uma rotina de pensamento na produção de significados aos indivíduos, a partir de suas interações com seus componentes.

Conceitualmente, Ferrara (2007) descreve a possibilidade de leitura sem palavras do espaço urbano. Nessa leitura, a comunicação não verbal, ou seja, aquela oriunda da percepção individualizada, pode ser comparada à leitura na comunicação midiática, adornada das representações da paisagem. Assim, na condição comunicativa própria da forma urbana, pretende-se discutir as ações dos signos da paisagem, gerando o entendimento de lugar, espaço e território.

\section{O espaço urbano como comunicação}

Em se tratando de comunicação, coloca-se a questão: em que área do conhecimento o espaço urbano é tratado? De modo habitual, esse espaço compõe um cenário, onde componentes físicos naturais e antrópicos estão na paisagem percebida. Entretanto, urbano compreende o resultado do modo de vida econômico e social, gerado por significados históricos, artísticos e culturais, formando, além da expressão e conteúdo, sentimentos e memórias nos indivíduos nele presentes. Enquanto território, projeta a institucionalização, constituindo regras e organização do lugar.

Logo, o espaço urbano como comunicação pressupõe troca de mensagens, mediadas ou não por algum artifício. Certo que há uma 
configuração perceptível, presente no desenho e morfologia tridimensional dos lugares, constituindo índices de ocupação referenciados à intensidade e modo de uso (MAGALHÃES, 2001). Entretanto, há, também, componentes não físicos, retratados em elementos imagéticos. Assim, o espaço urbano comunica a imagem de sua paisagem, compreendendo representações com potencial ilimitado de interpretações.

Em uma visão contemporânea, Duarte (2006) define a percepção do espaço urbano como resultado das apreensões de elementos concretos e das projeções mentais dos indivíduos sobre os mesmos. Isto é, a percepção se realiza em uma relação de reflexão e projeção de estímulos, para a qual o autor denota o termo cidade comunicada à ação projetada, como o que ocorre na mídia, determinada nos modos de reflexão e projeção. O primeiro representa a reflexão do objeto de estudo nos meios de comunicação e o segundo, consequentemente, sua projeção, obtida do marketing e da divulgação, determinada no entendimento de uma cidade desejada - aquela comunicada.

Por outro lado, buscando-se compreender como o espaço urbano gera essa paisagem comunicada, há de se considerar não somente o que está presente e exposto a todos os sentidos, mas também suas imagens invisíveis, contextualizadas nas impressões de cada indivíduo e nas intenções do arquiteto (MAZIERO, 2011).

Corroborando com Pignatari (2004, p. 119), a interpretação desses significados constitui, em geral, entendimento diferente entre indivíduos e, ainda, pode ser diferenciado daquilo que fora projetado:

O significado de um signo é um outro signo. Podemos acrescentar: dentro do mesmo código e/ou extra código, num processo necessário de intersemiotização. O significado de uma arquitetura é outra arquitetura, o significado de uma igreja é outra igreja - até a primeira, quando, conforme Hegel, um deus a habitou (PIGNATARI, 2004, p. 119).

\section{A percepção da paisagem como um sistema de informações}

A paisagem é definida por Macedo (1999) como sistema e produto. Configurada em sistema, apresenta reações às ações que lhe são impressas, como as alterações morfológicas resultantes dos diferentes modos de ocupação. Como produto, define-se no resultado dos processos de ocupação e gestão sobre ela. Todavia, a paisagem denota, também, como a relação do homem determina marcas, resultantes dos registros 
de intervenção em tempos diferentes. Nesse sentido, corroborando Ferrara (2007), o fator tempo amplia e dimensiona, gerando um macroespaço, no qual são perceptíveis essas marcas. Muitas vezes, elas são de natureza física, outras, social, expondo significados emocionais e culturais resultantes da percepção e, consequentemente, do modo de pensar das pessoas.

De acordo com Magalhães (2001), a paisagem urbana é formada por uma sobreposição de informações. Nela, o ambiente construído é dotado de significações, impregnado de emoções oriundas da história e vivência das pessoas. Entretanto, a apreensão desses significados ultrapassa o nível dos sentidos na percepção e dependem do processo cognitivo de seus usuários, em suas experiências, interações, memórias e vivência temporal (MAZIERO, 2011).

Nesse sentido, Ferrara (2007) defende que na cognição, a percepção não está no objeto, mas no modo de pensar das pessoas. Isto é, a percepção ocorre por meio dos sentidos na formação do pensamento, e deste à construção de sentimentos, que proporcionam, dentre outros fatores, segurança, intimidade, conforto, fazendo as pessoas voltarem ou não a interagir naquele lugar.

Para Tuan e De Oliveira (1983), são variadas as maneiras como pessoas percebem e avaliam um lugar. Percepções são diferentes entre indivíduos e dependem do modo como os espaços são usados e apropriados, transformando-se em lugar. Isso ocorre, principalmente, pela construção de sentimentos relacionados ao bem-estar.

Por outro lado, o modo como a informação é apresentada no ambiente urbano também é influenciado pela indústria cultural, que se baseia em processos de significação em massa. Nesse sentido, Coelho (2006) defende que, diante de uma indústria cultural gerada a partir da informação midiática, é fundamental focar na reorganização de um pensamento individual, ante a alienação coletiva.

Com base na psicologia cognitiva, Sternberg (2000) apresenta a percepção dependente de algum - ou alguns - dos sentidos do indivíduo (visão, audição, sinestesia, olfato e paladar). Além de passar por processos internos da consciência, guiada por filtros, tais como omissão, generalização, distorção, dentre outros, a percepção depende de memórias e do modo de pensar, influenciado por crenças e valores de cada indivíduo. Somada ao conhecimento adquirido, essa construção define as ações do indivíduo no ambiente em que vive.

Assim, a percepção da imagem de uma realidade não é direta. O conhecimento é construído em uma série de representações cognitivas, 
a partir de um complexo processamento mental da informação percebida. Há, primeiramente, reconhecimento, organização e compreensão de estímulos presentes no meio, para então gerar comportamentos (MAZIERO, 2011).

Logo, na configuração da paisagem como sistema de informação, tem-se a interseção das diversas tipologias componentes, como seus ocupantes, sua estrutura e significados gerados. Disso resulta a percepção das variadas linguagens do meio, definidas em diferentes escalas de visualização e em um espaço temporal, gerando um modelo mental, que Lynch (2010) conceituou como imagem individual.

\section{A semiótica na paisagem}

A paisagem é uma composição de signos, não tendo, necessariamente, natureza de linguagens estabelecidas, pois essas podem ser resultantes, por exemplo, da ação e reação (provocada em um movimento), da emoção (sentimento de prazer de estar em algum lugar) ou da imaginação (um pensamento ilimitado decorrente das mais variadas sensações). Possui também códigos de naturezas distintas, nos quais não são perceptíveis sinais de sua existência, como os de uma linguagem sincrética (NIEMEYER, 2003).

As linguagens da paisagem relacionam condicionantes sensoriais, culturais e temporais, que se interpõem na relação do observador e realidade observada, sendo assimiladas nas interações com o meio (TURIN, 2007). Assim, a leitura dessas linguagens admite questão de subjetividade, na construção de imagens tanto individualizadas quanto coletivas (PANERAI; DEPAULE; DEMORGON, 2005).

Pela teoria semiótica de Peirce (1999), os signos apresentam-se em três tipos: ícone, índice e símbolo. Entretanto, dificilmente se pode constatar a ocorrência do signo em apenas uma dessas categorias. Nesse sentido, Pignatari (2004) discute como a mensagem arquitetônica é desencadeada por meio de signo icônico - tridimensional e visível, passando à configuração de índice e símbolo a partir de suas inter-relações. Contudo, essa objetividade não é evidente, porque no processo cognitivo a percepção de um signo gera novos signos e novos significados, livres na interpretação do indivíduo.

Diz-se ícone àquilo que é primeiro e original. Nesse sentido, a caracterização de um signo icônico é obtida a partir de percepção ao acaso, original, livre e imediata, proporcionando ao indivíduo sentimentos de 
qualidade desde o início da percepção. Como sintaxe, a seleção dos componentes do meio, em hierarquia de formas na composição dos espaços, é livre de qualquer significação.

Seguindo esse raciocínio, ainda com base em Pignatari (2004), as formas do espaço urbano constituem um mundo icônico, sendo que a partir delas se efetuam sistematicamente novas leituras e novas interpretações. Assim, no nível chamado por Peirce (1999) como primeiridade, têm-se as qualidades perceptíveis do meio que provocam sensações no indivíduo, abrangendo tanto a percepção visual quanto as demais. Essas qualidades significantes provêm meramente do sentimento imediato e presente nas feições representadas, livre de outras interpretações. Nesse nível constituem-se qualidades abstratas, decorrentes da cognição produzida pelos signos, gerando sentimentos no processo de pensamento do indivíduo, tais como leveza, fragilidade, pureza e força, oriundas da composição da forma, cores, linhas, volumes, dimensão, textura, luminosidade, dentre outras.

Com as inter-relações provocadas no pensamento, signos passam a manifestar sua funcionalidade e intenção, proporcionando entendimento sob uma relação direta da composição formal com seu objeto (SANTAELLA, 2005). Nesse nível, signos são índices e demonstram ação e reação dos fatos concretos existentes e reais. Esses podem ser vistos na dimensão estrutural das cidades, como, por exemplo, no sistema viário formado por eixos e malhas, ou nos componentes do zoneamento urbano, indicando sua função e intenção. No nível da secundidade (PEIRCE, 1999) encontram-se traços, rastros ou indícios que denunciam a intenção, indicando a existência real, formados por signos entendidos na composição, forma, tamanhos ou matéria, vistos em função da manipulação ou uso. Para Pignatari (2004), esse é o nível da semântica, em que coexistem as relações entre o significado dos signos e o contexto ao qual pertencem, indicando sua origem, hábito de uso ou usuário a que se destinam.

Enfim, na função simbólica, tem-se na paisagem urbana uma interpretação arbitrada, ou seja, um entendimento convencionado pela comunidade ocupante, formando uma imagem coletiva de algo que não é perceptível pelos sentidos. Para Pignatari (2004), o uso efetivo dos signos arquitetônicos nem sempre leva o usuário a uma compreensão imediata de seu simbolismo, pois esses dependem da interpretação do usuário das mensagens projetuais atribuídas pelo arquiteto. Logo, no nível da terceiridade, está o poder representativo do signo na definição 
das relações deste com seu objeto, levando ou não à consolidação de um entendimento coletivo. Enquanto pragmática, nesse nível tem-se um ponto de vista sociológico na paisagem, como na definição de quem usa um lugar ou em que situação é utilizado.

Destarte, a análise pela abordagem semiótica constitui um referencial para a significação da paisagem. Nessa análise identifica-se como os signos produzem significados a partir de representações físicas ou mentais, desencadeando na mente um processo ilimitado de significação. Nesse contexto, o signo possui relação triádica, para a qual Peirce (1999) referiu-se aos três constituintes como signo, a coisa significada e a cognição produzida na mente da pessoa (SANTAELLA, 2005). Essencialmente, os signos substituem os seus objetos e se apresentam no ambiente urbano, tanto na composição formal quanto em componentes estruturais, ou ainda como marcos referencial e temporal.

\section{Metodologia de análise pelo processo de significação}

Para Turin (2007), a análise semiótica é uma abordagem na qual se busca a revelação do potencial comunicativo daquilo que está representado. Assim, na configuração da paisagem, busca-se compreender como significados são formados, como se configuram em linguagens e que tipos de efeitos podem gerar no intérprete. Logo, signos projetados e percebidos pelo indivíduo no espaço urbano se manifestam em uma mesma representação (veículo signo), inicialmente apreensível a partir de suas manifestações externas, como em composições plásticas da forma (KOHLSDORF, 1996). Contudo, nada assegura que o significado individual corresponda ao significado coletivo. Isto é, a interpretação de cada indivíduo pode ser diferente, pois signos do espaço urbano carregam tanto referências espaciais quanto temporais, o que resulta em novas possibilidades de interpretações a cada momento.

Analisando-se o ambiente urbano sob o ponto de vista semiótico, busca-se compreender, por meio das linguagens presentes, os aspectos de comunicação que relacionam identidade aos aspectos icônicos, estrutura aos indiciais e significação dos lugares aos aspectos simbólicos. Contudo, as características que compõem a paisagem são múltiplas e apresentam-se entrelaçadas na percepção, tornando esta um processo intuitivo e global, pois elementos que aparentemente apresentam-se dispersos podem proporcionar inspiração imprevisível. 
Observa-se, assim, que a comunicação do espaço urbano ultrapassa a representação imagética, contemplando também o modo de pensar. Em outras palavras, por meio da memória são recordados conhecimentos e experiências passadas, influenciando o modo de agir no momento presente.

Para tanto, a análise proposta neste trabalho segue um roteiro conceitual construído com base em Santaella (2005) e definido em um processo de pensamento sob a lógica cognitiva. Nessa abordagem distinguem-se três componentes de interpretação semiótica - primeiridade, secundidade e terceiridade (PEIRCE, 1999), que são indissociáveis, mas que podem ser considerados isoladamente para fins de estudo. Adota-se um primeiro nível de análise: qualitativo icônico - qualidades visíveis, abstratas e produzidas; um segundo nível: singular indicativo - traços da existência, aspectos de relação e de comparação; e um terceiro nível: convencional simbólico - interpretante imediato, dinâmico e final (SANTAELLA, 2005).

\section{Discussão dos resultados}

Para a análise semiótica da paisagem, foi escolhido o parque High Line (HIGHLINE, 2013), situado em Manhattan, na cidade de Nova lorque, Estados Unidos, com o qual se abordou o roteiro conceitual apresentado no item anterior. Esse recorte da paisagem urbana denota um parque contemporâneo de relevância internacional.

A área ocupada pelo parque teve anteriormente outra função, a de uma ferrovia, parcialmente demolida em 1960, deixando de ser usada totalmente em 1980. O local permaneceu em degradação por mais de 20 anos, até a realização do parque. A estrutura linear atravessa a cidade em aproximadamente $2 \mathrm{~km}$ de extensão e, em alguns locais, encontra-se elevada até $9 \mathrm{~m}$ de altura do nível da rua (Figura 1 ).

\section{Análise do primeiro nível: qualitativo icônico}

Na análise semiótica, geralmente é mais evidente a identificação e interpretação de signos indiciais e simbólicos. Contudo, o processo de pensamento deve iniciar na base da percepção, ou seja, com as primeiras 

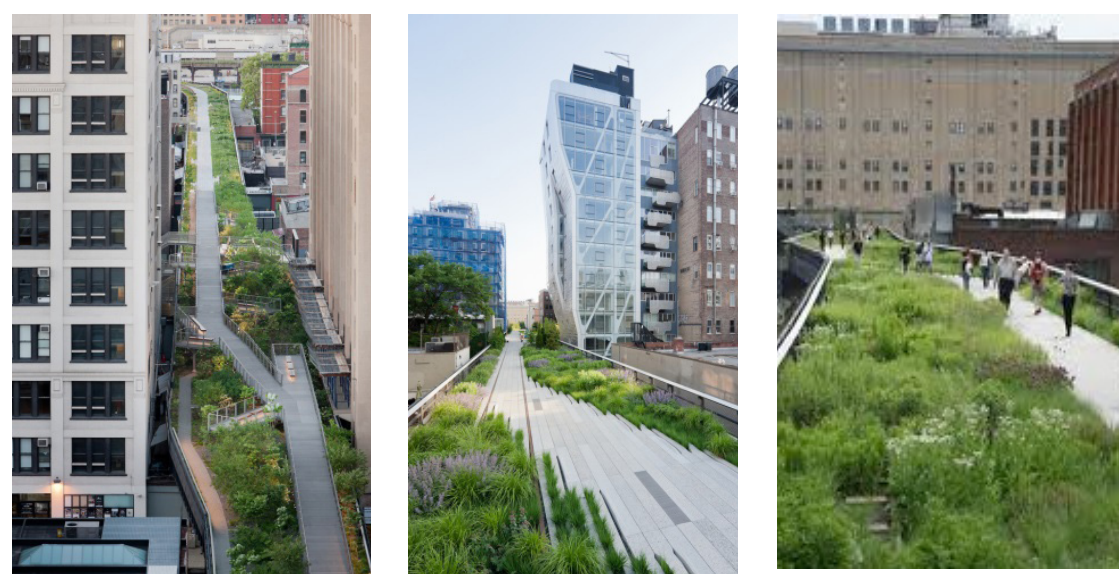

Figura 1 - Vistas do Parque High Line, em Manhattan, Estados Unidos. Fonte: HIGHLINE, 2013.

impressões. Esse processo é frequentemente dificultado por ter-se a memória infectada do conhecimento coletivo, sendo necessário despir-se de todo e qualquer conhecimento, deixando entrar na lógica cognitiva da busca e compreensão da essência da criação do objeto de estudo.

Assim, nesse nível é moldada a identidade do lugar, oriunda de um conjunto de sensações provocadas pelas inúmeras variantes perceptíveis do espaço, sendo essas abstratas - como nas primeiras sensações, obtidas da primeira impressão, brotada da primeira olhada; gerando, em sequência, na contemplação, sentimentos de prazer, de bem-estar, de efeito estético, dentre outros. Por fim, tem-se comparações por semelhança.

Desse modo, características icônicas podem ser vistas (Figura 2), como refletidas no ambiente pelas suas qualidades visuais, e percebidas de modo individualizado, a partir das tipologias morfológicas. Por meio dos sentidos do indivíduo, as percepções são possíveis: visão, nos ritmos das colocações materiais, bem como nas proporções, harmonias, cores e formas; olfato, nos odores do lugar, das pessoas, das flores; sinestesiaem texturas materiais; audição, vento, movimento das pessoas, veículos no entorno, barulhos da cidade; e paladar (por que não?), o sabor da neblina ou da poluição.

Remetendo à natureza, a imagem esquerda na Figura 2 proporciona sensações de serenidade, delicadeza, luminosidade e fragilidade. Por semelhança, nas imagens percebem-se fortemente marcas do tempo, remetendo à impressão de que o espaço não foi alterado. Ainda, nas imagens da Figura 2, restos da estrutura da ferrovia podem ser vistos criando uma 


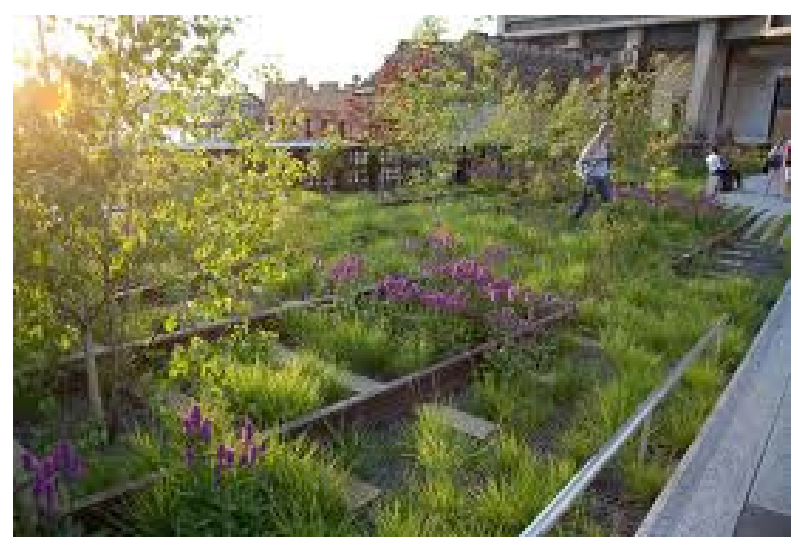

Figura 2 - Vistas de características icônicas e resgate de marcas do lugar do Parque High Line, em Manhattan, Estados Unidos.

Fonte: HIGHLINE, 2013.

aparente ligação de tempo e natureza, propiciando além da qualidade visual, um sentimento de que o parque projetado parece ser o próprio lugar original. Do mesmo modo, a percepção de bancos produz a sensação de que as pessoas aguardam a chegada do trem que ainda passaria por ali.

A percepção depende também das crenças e valores que cada indivíduo possui em relação ao ambiente, gerando qualidades produzidas, tais como a associação de ideias, generalização do todo ao particular e observação de fenômenos existentes. Assim vão se formando, em seu intelecto, aspectos da identidade do lugar, pelas representações estabelecidas em um sentimento imediato, como o que o lugar e o espaço proporcionam ao indivíduo no momento da sua interação. Nesse sentido, a imagem central na Figura 3 mostra um espaço em madeira, com aberturas como se fossem janelas. Nesse local, pessoas sentam e observam a paisagem. Contudo, não mais uma paisagem a partir de um trem em movimento, mas sim pela comparação de experiências já vividas, o que dá passagem a um segundo nível da percepção.

\section{Análise do segundo nível: singular indicativo}

Neste nível, a leitura é efetuada na percepção dos componentes do meio, tendo em seus indícios o entendimento de função e uso. Na semântica, aspectos indiciais constituem a atribuição de valores que regem seu modo de apreensão por relação e comparação. 

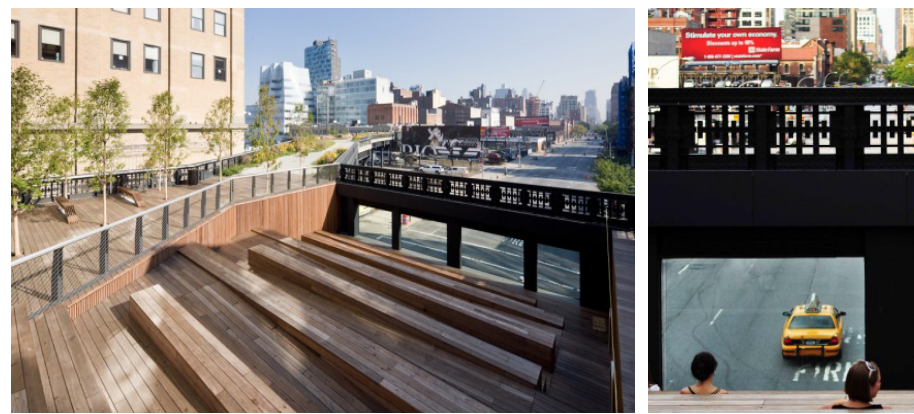

Figura 3 - Vistas de características icônicas (esquerda) e resgate de marcas do lugar (direita) do Parque High Line, em Manhattan, Estados Unidos.

Fonte: HIGHLINE, 2013.

Nesse sentido, o entendimento do espaço como lugar é obtido a partir das percepções do indivíduo com referência às experiências ou conhecimento de vivência já praticada com elementos presentes. Esse nível precisa de referência ou comparação, apresentando-se ao olhar como novos signos dotados de novas significações e, portanto, proporcionando novas possibilidades de entendimento (imagem central da Figura 3).

Esse é o nível de uma existência concreta. Busca-se referência às funções práticas do lugar, como sua estrutura física e de informações. Esses aspectos são resultantes da relação direta de existência do signo com seu objeto. Os traços da existência ou marcas na paisagem são oriundos da manipulação e do uso do lugar.

Levando-se em conta o mesmo conjunto de elementos da percepção inicial, agora são estabelecidas relações com o contexto a que pertencem ou a seu uso. No sentido indicial, o projeto resgata as referências do entorno, como visto nos rastros do trilho do trem e na característica de uma vegetação que nasce nas frestas do piso, imitando a presença da vegetação de um terreno natural (imagem esquerda na Figura 4), resultado do abandono do local por mais de 20 anos.

O sentido indicial aparece também em linhas norteadoras, como na presença de trilhos de trem, conferindo organização espacial e orientação. Além disso, como nas formas geométricas e retilíneas que se confundem com o desenho da cidade (imagem direita na Figura 4). Com o intuito de integração, tanto uma passarela que atravessa o parque quanto os volumes espaciais seguem a morfologia urbana, passando a fazer parte dela. Tem-se a imagem da cidade que entra no parque e a do parque que entra na cidade. 

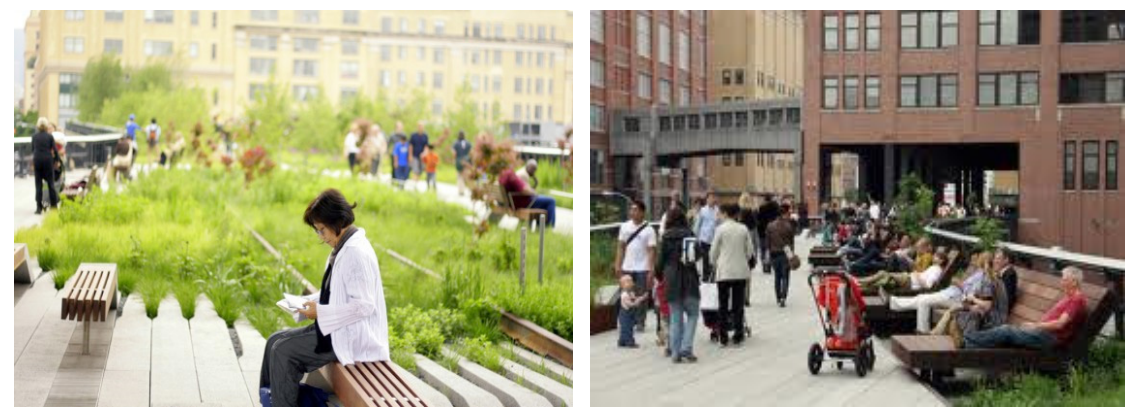

Figura 4 - Vistas de características indiciais e simbólicas - integração da cidade e pertencimento no cotidiano, do Parque High Line, em Manhattan, Estados Unidos.

Fonte: HIGHLINE (2013).

Dessa forma, esse espaço físico está hoje integrado ao espaço urbano; sua principal função é a revitalização proporcionada em toda a região de entorno. Na análise, nessa relação podem ser interpretadas as origens ou o hábito de uso: não há movimento de trem - ele não chega; ou a quem se destinam os espaços - não mais aos viajantes. A própria composição do espaço projeta suas novas funções para desempenhar as finalidades a que se presta, ou seja, proporcionar entendimento da sua estrutura e utilidade, como em um sistema de engrenagens - lugar de prazer, repouso, passagem, contemplação, e lugar de trabalho.

\section{Análise do terceiro nível: convencional simbólico}

No entendimento da paisagem como um sistema, elementos individuais passam a compor um modo de pensar coletivo, contagiando a percepção dos demais indivíduos. Parte-se de um interpretante imediato, resultado de relações convencionadas, que definem o espaço urbano como um produto em potencial. Nele, criam-se desejos, padrões de design, padrões de gosto e expectativas culturais. Desse modo, há qualidades produzidas, como o efeito perceptível de características conceituais projetadas. Essas determinam definições para os usuários, como o impacto ambiental, ou um novo contexto de uso: onde antes passava uma estrada de ferro, hoje passam pessoas (Figura 4). Na antiga área industrial da cidade, hoje se concentram as maiores galerias de arte, transformando o local em um reconhecido setor residencial histórico e criando uma estética idealizada. 
A própria percepção de abandono retratada na imagem do lugar (Figura 1), permanece existente no imaginário das pessoas e, como sentido simbólico, passa a existir a partir da interpretação de um significado histórico, arbitrado pela comunidade e referindo-se ao novo conceito do lugar. Surgem, assim, os efeitos das memórias acumuladas, por meio de um interpretante dinâmico, definido com regras e poder representativo. Essas memórias agregam valores culturalmente e constroem status. Inicia-se um processo de consolidação do pensamento, promovendo novas convenções, gerando comportamentos, que, no limite pensável, carregam novos valores como resultados dessa interpretação.

Nesse nível está o limite pensável, interpretante final - resultado da interpretação de algo que não é mais perceptível pelos sentidos, mas por sua função simbólica. No parque analisado, a integração do espaço à imagem da cidade, vista tanto nas características físicas do seu traçado (Figura 4) quanto no sentido de apropriação do lugar, remete fortemente ao aspecto simbólico. Ou seja, o parque passou a ter um significado de pertencimento à cidade, fazendo parte da sua imagem coletiva.

\section{Conclusão}

Este artigo faz uma intersecção entre conceitos clássicos de semiótica e o espaço urbano, propondo reflexão no modo de pensar a cidade. A semiótica não se apresenta apenas como gramática e classificação dos signos. Ela proporciona, também, uma análise sobre a cognição humana realizada nas ações dos signos (SANTAELLA, 2005). A semiótica está no modo de pensar, e como tal possibilita compreender as linguagens dos espaços urbanos, sejam elas produzidas pelo homem ou pela natureza.

A abordagem de pensamento, apresentada neste texto para leitura das linguagens do espaço urbano, expressa a subjetividade do efeito da imagem produzida, assim como da imagem interpretada. Desse modo, a análise foi direcionada para expor de modo didático a discussão gerada. Esta última cumpriu seu objetivo, mostrando a aplicação de uma análise com base na relação triádica da teoria de Peirce (1999), na qual signos fazem referência às suas representações, desencadeando na mente das pessoas um processo ilimitado de significação.

A cognição visual, como principal sentido, está no entendimento daquilo que o indivíduo vê. Contudo, ela acontece aos poucos e abrange as demais percepções, interagindo com fenômenos fisiológicos e psicológicos, enquanto as sensações vão se produzindo e sendo organizadas na 
mente dos indivíduos. Assim, a análise sob a perspectiva de significação é contínua, assegurando um modo de apreensão dos significados, tanto nos aspectos perceptíveis, quanto nos emocionais. Em outras palavras, é possível relacionar significados corporificados no espaço urbano com aqueles que existem apenas no imaginário das pessoas.

Para este trabalho, investigou-se um fenômeno real e contemporâneo, com a intenção de discutir a cidade sob o olhar da semiótica. Buscou-se, principalmente, compreender, por meio da comunicação dos espaços, como acontece a produção de significados, que ocorre na transformação de espaço em lugar, especialmente aqueles voltados à valorização do indivíduo e do coletivo.

Assim, a temática da comunicação do ambiente urbano pode trazer avanços nas abordagens conceituais e metodológicas, visando a um novo formato de produção de conteúdo sobre o modo de pensar as cidades.

\section{Referências}

COELHO, T. O que é indústria cultural. São Paulo: Brasiliense, 2006.

DUARTE, F. Rastros de um rio urbano: cidade comunicada, cidade percebida. Ambiente e Sociedade, v. 9, p. 105-122, 2006.

FERRARA, L. D'A. Leitura sem palavras. São Paulo: Ática, 2007.

HIGHLINE. The official web site of the High Line and Friends of the High Line. Disponível em: <www.thehighline.org/>. Acesso em: 2 jul. 2013.

KOHLSDORF, M. E. A apreensão da forma da cidade. Brasília: 1996.

LYNCH, K. A imagem da cidade. São Paulo: Editora Martins Fontes, 2010.

MAGALHÃES, M. R. A arquitectura paisagista: morfologia e complexidade. Lisboa: Editorial Estampa, 2001.

MAZIERO, L. T. P. Paisagem comunicada: parque linear no espaço cicloviário de Curitiba, Paraná, sob uma abordagem semiótica. 2011. 140 f. Monografia (Especialização em Paisagismo: Planejamento e Projeto) - Pontifícia Universidade Católica do Paraná, Curitiba, 2011.

MACEDO, S. S. Quadro do paisagismo no Brasil. São Paulo: Quapá; FAUUSP, 1999.

NIEMEYER, L. Elementos de semiótica aplicados ao design. Rio de Janeiro: 2AB, 2003. 
PANERAI, P.; DEPAULE, J-C ; DEMORGON, M. Analyse urbaine. Marseille: Parenthèses, 2005.

PEIRCE, C. S. Semiótica. São Paulo: Perspectiva, 1999.

PIGNATARI, D. Semiótica da arte e da arquitetura. Cotia: Ateliê, 2004.

SANTAELLA, L. Semiótica aplicada. São Paulo: Thomson Learning, 2005.

STERNBERG, R. Psicologia cognitiva. Porto alegre: Artes Médicas Sul. 2000.

TUAN, Y.; DE OLIVEIRA, L. Espaço e lugar. São Paulo: DIFEL, 1983.

TURIN, R. N. Aulas: introdução ao estudo das linguagens. São Paulo: Annablume, 2007.

Recebido: 04/07/2013

Received: 07/04/2013

Aprovado:10/09/2013

Approved: 09/10/2013 